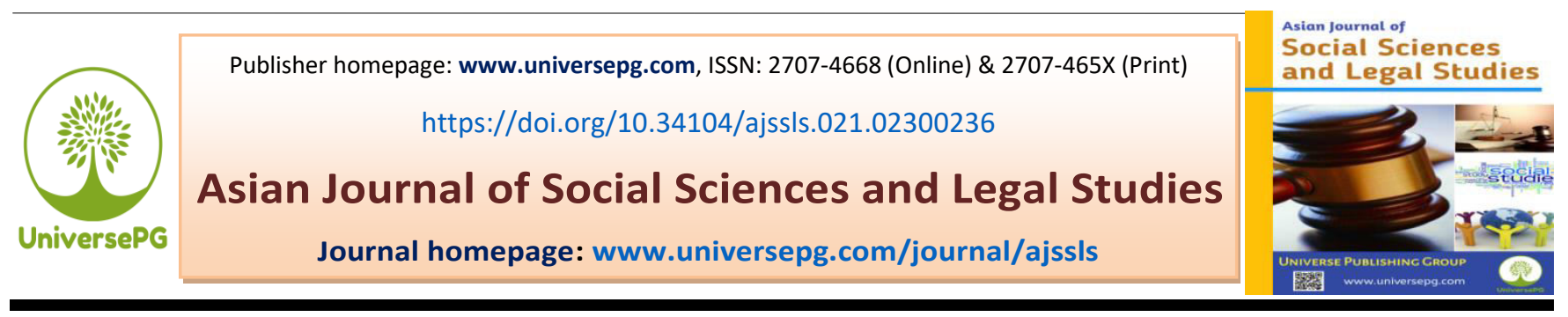

\title{
New Public Management in Bangladesh: Implementation Challenges and Ways Forward
}

\author{
Shajada Ahsan Habib ${ }^{1}$ and Nazmul Hasan ${ }^{1}$ * \\ ${ }^{1}$ Department of Public Administration and Governance Studies, Jatiya Kabi Kazi Nazrul Islam University, Trishal, Mymen- \\ shing, Bangladesh. \\ *Correspondence: nazmul.pags23@ gmail.com (Nazmul Hasan, Lecturer, Department of Public Administration and Governance \\ Studies, Jatiya Kabi Kazi Nazrul Islam University, Trishal, Mymenshing, Bangladesh).
}

\begin{abstract}
New Public Management (NPM) is currently a global trend that is dominating all governments' reform agendas. Bangladesh is not an outlier. This paper begins by defining NPM and then moves on to examine critical preconditions for successful NPM implementation. Following that, this research revealed significant roadblocks in Bangladesh's implementation of modern public management. The final section of the study focuses on the next steps in implementing modern public management in Bangladesh and concludes with a final comment on the overall concept.
\end{abstract}

Keywords: New public management, Implementation, Administrative reform, and Bangladesh.

\section{INTRODUCTION:}

NPM might become a comprehensive extension of New Public Management. The term "new public management" refers to a method of administering government agencies. The phrase was used by academics in the United Kingdom and Australia in the 1980s to describe measures that were created in the context of an attempt to make the whole public service more "business like" and efficient by utilizing non-public sector management paradigms. Citizens are referred to as "customers" under NPM, and public servants are referred to as "public managers." Value worth, characteristic, financial management, boosting efficiency, creating goals and continuing to keep an eye on performance delivery, and power to top management executives were key elements in New Public Management (NPM).

NPM is also said to have been adopted in response to growing global demand for "good governance" as well as the state's ever-changing role. NPM attempts to UniversePG I www.universepg.com avoid the criticism leveled at previous public administration by improving service delivery and potency, as well as implementing accountability. In contrast to traditional government, NPM focuses on the outcomes rather than the method of execution.

In contrast to traditional public administration, which used to burden the government with implementing too many activities at the same time with no involvement of the private sector or NGOs, NPM strongly supports the involvement of the private sector and nongovernmental organizations (NGOs) in the delivery of services (Mamun et al., 2021; Sharma, 2007).

\section{Literature Review}

Since the 1980s, NPM reforms have spread across various rich and developing nations with the full assistance of international organizations. It appeared as a result of ancient governmental administrations all over the world attempting to be ineffectual and failing 
to take into account basic environmental influences of commercial activity (Kalimullah, Ashraf et al., 2012). The model's well-built nature is support for absorption of private sector potency, effectiveness, and fight in public sector reorganization and management. It comprises of a wide-ranging front publically sector structure designed to induce improved performance by implementing a series of planned modifications to the public sector's structures and procedures (Governance 2002; Arora 2003; Ehsan and Naz, 2003). NPM reforms denote a change in emphasis from traditional public administration to modern public management. Furthermore, the concept emerged from the belief that the forms of public organizations had deteriorated and needed to be restored through a new management paradigm (Savoie, 2006). NPM might be a catch-all term for a slew of changes sparked by the idea that private-sector management approaches are needed to boost government potency, effectiveness, and efficiency (Fatemi and Behmanesh, 2012). These measures include introducing body structures, increasing the responsibilities of public administrators, submitting market processes, and introducing quality management approaches into the public sector (Rahman et al., 2013). NPM is defined by (Van et al.,2015) as the introduction of non-public sector concepts and techniques such as outcome-based accountability and market-driven management into the public sector with the goal of increasing the public sector's potency and effectiveness, sweetening organizations' responsiveness to a national level, lowering public expenditures, and improving social control accountability. In a similar vein, (Sulle, 2011) did a study titled "Result-Based Management in the Public Sector: A Decade of Expertise for Tanzanian Government Agencies." The adoption of result-based management in the public sector of African countries is one of the NPM-inspired changes, according to the research. The study looks at how far the managing agency management was able to rebuild and convert to the NPM result-based approach. According to the findings, a result-oriented strategy has been partially implemented in the public sector in African countries, with reduced reliance on management for outcomes but still relying heavily on inputs and procedures. According to the most current analysis papers, while there is some analysis work on new public management in numerous nations throughout the world, there is a significant lack of analysis on the implementation of recent public management in Bangladesh. The purpose of this book is to discuss the obstacles that have arisen as a result of Bangladesh's new public management implementation, as well as the steps that may be taken to address those concerns. As a result, may be our study will help to close the gap.

\section{Objectives of the Study}

The purpose of this study is to determine whether or not new public management (NPM) has been successfully implemented in Bangladesh. The study also aims to investigate the idea and prerequisites for effective implementation of modern public management. The research also seeks to describe the many stumbling obstacles of modern public administration in Bangladesh in order to attain this goal. In the final section of this research, we'll look at how to get to a more effective new public management in Bangladesh.

\section{METHODOLOGY:}

This is a qualitative study and the nature of the study is analytical, focusing on qualitative data gathering mainly from the secondary sources because they are relevant, reliable and authentic source of information to achieve the objective of this study. The study will be desk-based through the use of secondary data. Data sources include analysis of newspaper reports, book, journals, articles and different websites.

\section{Definition of New Public Management (NPM)}

New public management, according to the OECD, might be a new paradigm for public administration that aims to develop a performance-oriented culture in a decentralized public sector. According to Hood, New Public Management is a global or even international development that represents a test to correct the shortcomings of ancient public organizations in terms of potency and service delivery to voters, with one of its central themes being the importance of public managers' discretionary house or management freedom. New Public Management, according to Mongkol, is a set of unique management ideas and practices that are mostly drawn from the private sector and adapted to the public sector. New Public Management (NPM) is a method of managing public-sector organizations that is used in government and public-sector enterprises and agencies at all levels of government, including subnational and 
national levels. Pollitt, (2001) focused the most components of NPM as follows:

1) A shift in the focus of management systems and effort from inputs and processes to outputs and outcomes.

2) A shift toward more comprehensive measurement, as manifested in performance indicators and standards.

3) Preference for specialized and independent organizational structures over large, multi-purpose, ranking bureaucracies.

4) A large number of pact or contract-like ties have been substituted for ranking relationships.

5) Market-oriented or market-like processes for delivering governmental services (such as privatization, acquisition, and the emergence of internal markets).

6) The "frontier" between the public and private sectors is broadening and blurring (as evidenced by the proliferation of public-private partnerships of various types and the apparent proliferation of "hybrid" organizations).and

7) Price priorities are shifting away from theological doctrine, equity, security, and resilience and toward potency and individualism.

\section{Precondition for successful implementation of NPM}

The institution of meritocracy, robust institutional frameworks, the rule of law, accurate management structures, checks and balances, and trustworthiness among public administration systems are all centered on the level of economic growth and basic public administration processes.

\section{Capability of the state}

The natural circumstances are blamed for the state's failure to foster political and social thought. This has aided the state in becoming extremely cost-effective and capable, as seen by a certified public sector and, as a result, the isolation of state calls makers from consumer list teams.

\section{Institutional capability}

Institutional capability is defined as a country's ability to uphold its government's authority, adopt and enforce laws, and hold people responsible under those laws (Wallis and Dollery, 2001).

\section{Technical capability}

Once important decision-making bodies staffed by qualified personnel are shielded from the demands of unproductive clients list teams, technical capability becomes clear (Wallis and Dollery, 2001).

\section{Administrative capability}

The ability of a state to perform fundamental administrative activities and provide basic human services is referred to as administrative capability. Typically, this is especially important at this stage because of the NPM reform package's considerations. Several NPM initiatives, such as privatization, corporatization, and obtaining out, are predicated on administrative incapacity. However, Wallis and Dollery, (2001) point out that, in the absence of the state's efficient role in performing minor functions such as providing public goods and services, economic infrastructure, law and order, and the judiciary, the state is unable to carry out grand privatization, corporate, and obtaining out programs (Wallis and Dollery, 2001).

\section{Political capability}

Political competence refers to the state's ability to manage conflict, respond to subject requests, allow for the representation of interests, and give possibilities for successful political engagement at various levels. It also helps to maintain political stability and strengthen the state's core legitimacy (Grindle, 1996).According to Osborne and McLaughlin (2002), there is four different stages of public administration development: (1) the insignificant state; (2) the uneven partnership between government and the charity and commercial sectors; (3) the welfare state; and (4) the plural state.

\section{Implementation challenges of new public manage- ment in Bangladesh}

\section{Colonial bureaucratic Culture}

Asian nation, like many other post-colonial nations, inherited a robust bureaucratic structure from its colonial overlords (Alavi, 1979). However, it has received harsh criticism for its performance throughout the years. There are several issues about how Bangladesh's general public administration operates. The bureaucracy has been embroiled in opaque and damaging activities. Widespread financial distress, erosion of law and order, insecurity of individual rights, violations of traffic laws, and a wide range of other activities have 
all become commonplace in national life. These are the outcomes of a predatory attitude to governance duty (Daily Star, 2001; Sobhan, 2004).

\section{Lack of Political Commitment}

The political leadership has never been serious about reforming the executive branch (Khan, 1998). During the electoral campaign, the major political parties have consistently emphasized the need to overhaul the executive structure. They never transform their intentions into reality when they assume power. Because the political leadership believes the immediate political costs of administrative changes exceed the longer-term benefits, short-term political calculations have dominated decision-making. As a result, in Bangladesh, political commitment is limited by client list politics, which is to blame for diverting the political leadership's attention away from substantial reform projects (World Bank, 1996; Sarker, 2004; Sobhan, 2004).

\section{Lack of State Capacity}

In Bangladesh and other developing nations, state competency remains a substantial impediment to NPMstyle changes (Sobhan, 2004; Arellano-Gault, 2000; Heredia and Schneider, 1998). The message is simple: we'd prefer "government" before we try to "reinvent" it. In recent years, numerous developing countries, such as Bangladesh, have seen serious institutional failures. The Bangladeshi government's institutional incomepetence may be shown in its failure to sustain power in a variety of areas. The feature may be seen in all areas. In addition, the government's inability may be shown in government and enforcing laws, as well as holding government officials accountable under such laws (Yunis and Mostafa, 2000).

\section{The interference of international donor agencies:}

As an aid-dependent country, Asia has always been vulnerable to foreign donor influences when it comes to drafting and reformulating its reform program. Donor agency recommendations for administrative improvements in Asian countries have had minimal effects. During this time, a variety of things will be detected. Because the donor agencies did not build political leadership, the public bureaucracy believes that their prescriptions will produce favorable effects. The 1996 World Bank research might serve as an example Comprehensive reform plans based on the NPM paradigm were suggested. The native political and officialdom UniversePG I www.universepg.com leadership, on the other hand, showed little respect for the proposed reform measures (Khan, 1998; Schacter, 2000). Furthermore, there is a lack of understanding of local situations such as high levels of corruption, a lack of basics in public management, and a serious governance crisis (Sobhan, 2002, 2004).

\section{Corruption}

Corruption has direct consequences for NPM-style changes. Despite the fact that NPM's prescriptions of catching out and privatization appear to be effective in combating corruption, it is suggested that a system already plagued by over-politicization and corrupt practices might provide more chances for personal gain and patronage distribution (Turner and Hulme, 1997; Hughes, 1998; Haque, 2001). The privatization of stateowned firms is already showing signs of catching up (Akram, 1999; Uddin, 2005; Sarker, 2001).

\section{Victim of Politicization}

The civil service of Bangladesh has long been a victim of politicization. It has a significant influence on decision-making inside the bureaucracy. The long-term advantages of change always surpass the long-term time edges. Political leaders must have control over the resources and deliver rewards to party members. In ancient bureaucracy, it was customary practice to maintain the personal perks of bureaucrats and politicians. As a result, bureaucrats and politicians are hesitant to modify it. The developing nations that successfully implemented the NPM model were extremely cautious in selecting NPM-related items. This has not been done by the Bangladesh civil service.

\section{Lack of Basic Infrastructure of Management}

Because the basic infrastructure of management isn't developed enough to conduct market-oriented reform, new public management has failed to achieve nations, despite the fact that these countries demonstrate an enormous amount of fervor in pursuing these reform initiatives.

\section{Lack of Political Capacity}

Political backing is essential for the implementation of recent public management reforms in Bangladesh. However, the lack of strong political structures, political antagonism, political legislation, and political instability in Bangladesh make political capacity unnatural. As a result, NPM is not well enforced in Bangladesh. 
Lack of economic development and basic public administration processes

Bangladesh has yet to make significant economic progress. It is not focused on the meritocracy institution, strong institutional frameworks, the rule of law, proper management structures, checks and balances, and accountability in the public sector. On the other side, Bangladesh has no capability development within the public sector, which prepares the way for economic modernization and further administrative modernization based on the NPM logic.

\section{Over-ambitious, not appropriate \& not-adopted}

NPM appears to be overly ambitious, inappropriate, and unsuited to the local environment and political realities, as the institutional and structural structures in industrialized nations and Bangladesh are vastly different. Furthermore, the government has often grudgingly accepted its components. As a result, while NPM may provide secure benefits in some circumstances, it may be counterproductive in others, potentially contributing to worse performance and political instability.

\section{Poor cultural ecology}

The NPM projects are also influenced by cultural ecology. They might have a big impact on how the NPM model is used. Bangladesh has cultural value because of its large power distance, collectivism, masculinity, the importance of 'face,' and hence the value of family support. As a result, corruption is more difficult to prevent here, and merit-based accomplishment is hampered by favoritism, which is incredibly difficult to alter. It demonstrates how formal processes are subordinated to the informal order established by social networks and client list lobbying. As a result, cultural diversity has become a barrier to NPM components, and values have been mobilized to preserve power structures and, as a result, the status of bureaucracies and functionary types of organizations.

\section{Lack of Cooperation and support}

Collaboration and support from the general public are also crucial prerequisites. Bangladesh, on the other hand, confronts a lack of respect and support from the United Nations agency area unit in charge of reform implementation. They see NPM as a devaluation of their gift status, position, and power. They have a tendency to maintain the status quo by creating opposition UniversePG I www.universepg.com in order to divert attention away from related change efforts.

\section{Lack of Institutional capacity}

The state of the country's rule of law is reflected in institutional competence. Bangladesh has a history of full-fledged institutional failures in a variety of areas. The collapse of law and order, as well as the emergence of massive corruption in the accumulation and distribution of resources, are all manifestations of institutional incompetence.

\section{Lack of Technical capacity}

Key decision-making bodies staffed with qualified personnel and shielded from the demands of unproductive client list teams define technical competency. In Bangladesh, technical failure has also become a common occurrence. Bangladesh's government has failed to attract talented personnel, and advancements are based on a client list nexus and officials' party ties, rather than merit. Since 1971, every administration has attempted to court civil personnel for political gain. Again, the Public Service Commission is politicized by choosing people based on their political ties, who are then admitted under the spoils system, and therefore the selection process is altered to choose party loyalists. Bangladesh's struggle to complete fundamental bodily functions has been made more difficult by this politicization of forms. As a result, it confronts technical limitations such as a lack of qualified employees, poor performance management, and accountability.

\section{Lack of administrative capacity}

Administrative competence refers to a state's ability to carry out basic administrative responsibilities and protect fundamental human rights. Because the major function behind NPM implementation must be completed by bureaucrats, an unprecedented level of administrative organization is required. Some NPM components, such as privatization, corporatization, and getting out, utilize administrative incompetence as a justification. However, if the state is unable to perform fundamental public management duties such as the administration of public goods and services, economic infrastructure, law and order, and the court system, the state would be unable to carry out the major privatization, corporatization, and exit plans. Solid institutional frameworks, the rule of law, proper management structures, checks and balances, the civil service sys- 
tem, and accountability mechanisms, on the other hand, are either nonexistent or ineffective in Bangladesh. As a result, it has been administratively incapable of providing fundamental public goods and services, economic infrastructure, and a responsible judiciary, among other things.

\section{Ways forward of implementation new public mana- gement in Bangladesh}

The whole NPM paradigm has been implemented or is being considered for use in poor countries such as Bangladesh. Different governments in various parts of the developing world have only made piecemeal attempts.

\section{Decentralization}

Decentralization is a technique for spreading decisionmaking authority closer to the people. During decentralized governance, people still seek and need religion. As a result, financial transfer mechanisms, as well as methods for ensuring native level planning and budgeting, should be learned and integrated into national planning and budgeting. Each macro and minor facet of decentralization, i.e. political and bodily, as well as a shift in the perspective of government officials, must be observed. The MPs' informational function should be phased out. Making assured elections will not suffice. They should also be completely sceptered (Munira, 2014).

\section{De-bureaucratization}

De-bureaucratization is the process of reorganizing the public management system such that operations take precedence over structure. It entails changing the mindset of bureaucrats so that the specified protocol takes precedence above the outcomes (Munira, 2014). With the passage of time, it is hoped that the Bangladesh government would change its regulations to reflect dynamical desires. However, de-bureaucratization is not strictly implemented in Bangladesh. As a result, government de-bureaucratization should begin as soon as possible.

\section{Reducing wastage and promoting value for money}

Empowerment of the Comptroller and Auditor General's Office; rationalization of the public financial management system; elimination of irrational system losses in a variety of sectors; inclusion of the private sector in the transportation pool; enactment of a comprehensive consumer protection law; privatization of UniversePG I www.universepg.com state-owned enterprises among the ability of market absorption; streamlining rules to reduce corruption and waste of funds; transformation of existing public sector hospitals in to restricted companies; increase of user's fees in respect of services/utilities.

\section{Combating corruption}

Establishment of an Ombudsman; allowing more personal corporations to reduce monopolistic power; release of non-core operations; reduction of discretionary powers of public officials; revision of anticorruption legislation; establishment of a freelance Commission Against Corruption (ICAC).

\section{Progressing the delivery of services}

Delegation of powers to subordinate and field offices; separation and independence of the judiciary from the administration; creation of performance requirements and a citizen's charter; introduction of market-based orientated remuneration for public officials.

\section{Restructuring the Civil Service}

Merit-based appointment eliminates the cadre system's balkanization, increases competition for senior positions, improves pay at senior levels, links promotion to performance, extends rotation time in posts, strengthens coaching and development, and aligns wages and salaries with the cost-of-living index (Sarker, 2006).

\section{Reorganizing establishments and rationalizing man power}

The number of ministries was reduced since their activities were to be outsourced to the private sector. Because there are a lot of people in lower classes and a lot of people in higher grades, it was suggested that spare force be used to close the gaps (Sarker, 2006)

\section{Downsize the government}

Delegation of physical and monetary authorities down the hierarchy; decrease of government size; reduction of layers for call making (Farhana, 2013).

\section{Redefining frontiers of the public sector}

Increasing the degree and character of public organizations' accountability and responsiveness to various stakeholders; simplifying regulations, procedures, and processes; and retaining a cost-effective, devoted, and skilled public service (Farhana, 2013).

\section{Determination of missions of public offices}

Improving service delivery; reforming the civil service; forming a skilled political affairs group (senior mana- 
gement pool); reorganizing establishments and rationalizing manpower; restructuring field administration and decentralization; establishing an independent anticorruption commission; establishing a criminal justice commission; establishing an Ombudsman's office; reducing waste and promoting value for money; strengthening parliamentary oversight; facilitating private investment (Farhana, 2013).

\section{CONCLUSION:}

According to the findings of the study, implementing modern public management requires a number of requirements and is a huge undertaking in a post-colonial emerging nation like Bangladesh. The government's policy implementation is admirable, but the inability to raise awareness among the people for whom the program is executed is a major failing. In order to accomplish and raise public awareness regarding administrative reform, a dramatic shift is required. Some actions are more crucial than others in establishing modern public management in Bangladesh. Decentralization, de-bureaucratization, fighting corruption, improving delivery services, shrinking government, and determining the tasks of public agencies are among them. Overall, the NPM initiatives help to increase the quality of government operations and public services while also increasing citizen happiness.

\section{ACKNOWLEDGEMENT:}

Authors would like to thank Department of Public Administration and Governance Studies for providing continuous support.

\section{CONFLICTS OF INTEREST:}

The authors professed that there is no potential conflict of interest to publish this research paper.

\section{REFERENCES:}

1) Hughes O. E. (1998). "Public Management \& Administration," $2^{\text {nd }}$ ed., London: MacMillan.

2) Kalimullah, N.A. and Alam, K.M.A and Nour, M.M.A. (2012). New Public Management: Emergence and Principles, BUP JOURNAL, 1(1); 1-21. https://scsr.pravo.unizg.hr/_download/repository/122.pdf

3) Kalimullah, Nazmul Ahsan, Khan, S. M. Norman Hasan, (2011). New Public Management in Developing Countries: How far is it applicable in Bangladesh? In Bangladesh Journal of Administration and Management, 14; 1-22.

https://www.bup.edu.bd/system/uploads/journal/file /17/BUP JOURNAL 2012 compressed.pdf

4) Mamun HAR, Islam MT, and Islam Z. (2021). Personnel management in Bangladesh: from old public administration to new public management, Asian J. Soc. Sci. Leg. Stud., 3(4), 139-146. https://doi.org/10.34104/ajssls.021.01390146

5) Osborne, D. and T. Gaebler. (1993). Reinventing Government: How the Entrepreneurial Spirit Is Transforming the Public Sector. New York: Penguin Books.

https://www.amazon.com/Reinventing-Government -Entrepreneurial-Spirit-Transforming/dp/04522694 $\underline{23}$

6) Sarker A. E. and Pathak R. (2000). "New Public Management: An Analytical Review," Productivity, 41(1); 180-203.

https://doi.org/10.1108/09513550610650437

7) Sarker, A. E. (2006). New Public Management in Developing Countries: An analysis of success and failure with particular reference to Singapore and Bangladesh. International Journal of Public Sector Management, 180(203); 180-203. https://doi.org/10.1108/09513550610650437

Citation: Habib SA., and Hasan N. (2021). New public management in Bangladesh: implementation challenges and ways forward. Asian J. Soc. Sci. Leg. Stud., 3(6), 230-236. https://doi.org/10.34104/ajssls.021.02300236 @) 